\title{
SECULAR TRENDS IN THE PHYSICAL FITNESS OF UNDERWEIGHT, OVERWEIGHT, AND OBESE GIRLS
}

\author{
JERZY SACZUK¹, AGNIESZKA WASILUK² \\ Iózef Piłsudski University of Physical Education in Warsaw, Faculty of Physical Education and Sport \\ in Biała Podlaska, Department of Human Biological Development, Biała Podlaska, Poland \\ 2Józef Pitsudski University of Physical Education in Warsaw, Faculty of Tourism and Health in Biała Podlaska, \\ Department of Biomedical Foundations of Health Sciences, Biała Podlaska, Poland
}

\author{
Mailing address: Jerzy Saczuk, Józef Piłsudski University of Physical Education in Warsaw, \\ Faculty of Physical Education and Sport in Biała Podlaska, 2 Akademicka Street, 21-500 Biała Podlaska, \\ tel.: 83 3428741, fax: 83 3428800, e-mail: jerzy.saczuk@awf-bp.edu.pl
}

\begin{abstract}
Introduction. Along with the changing socio-economic status of the Polish society, differences in the nutritional statuses of children and adolescents as well as a decrease in their physical fitness are becoming apparent. The aim of the study was to determine ten-year changes in the physical fitness of girls with normal weight-to-height ratios compared to their underweight, overweight, and obese peers. Material and methods. A total of 5,760 girls aged 13-18 years were examined in 2006, and 2,669 girls were evaluated ten years later. The participants of the study underwent the Eurofit tests, and their height and weight were measured, which made it possible to calculate BMI. The subjects were divided into groups based on the recommendations of the International Obesity Task Force. Ten-year differences in physical fitness were expressed in T-scale points, and their magnitude was estimated using Student's t-test for independent samples. The frequency of underweight and excess weight was expressed in percentages, and the size of statistical differences between the groups was evaluated using the $\chi^{2}$ test. Results. During the decade analysed, the prevalence of overweight and obesity in the group of girls increased and that of underweight decreased. From 2006 to 2016, there were no significant changes in the physical fitness of the girls, neither in the calculations for the entire population nor in the group with normal BMI. On the other hand, an improvement in the level of physical fitness of underweight girls and its decrease in overweight and obese subjects were observed. However, the changes were not consistent across all Eurofit tests. Conclusion. The changes in the weight-to-height ratios and physical fitness of the girls who participated in the study show that there is a need to undertake inter-ministerial corrective actions aimed at increasing the physical activity of children and adolescents, with particular emphasis on students with excess body weight.
\end{abstract}

Key words: BMI, physical fitness, secular trend

\section{Introduction}

In many countries around the world, including Poland, the prevalence of overweight and obesity among children and adolescents continues to increase. This not only concerns countries which are highly economically developed but is also becoming noticeable in developing countries $[1,2]$. In addition, this trend is not evenly distributed throughout a given country but varies regionally. These observations have been confirmed by the study of Apfelbacher et al. [3], concerning the incidence of overweight and obesity among children from East and West Germany; the research of Fraser and Edwards [4], examining obesity in children and adolescents in Great Britain; and that of Grajda et al. [5], comparing obesity among the young inhabitants of Polish provinces.

Currently, no uniform global secular trends can be observed in physical fitness. Their direction and dynamics depend on the geographical location and economic development of the country whose population is analysed. Such conclusions were reached by Tomkinson et al. [6] based on research carried out on children and youth from 28 countries. Moreover, unfavourable changes in the physical fitness of children and adolescents have been observed in Japan [7], South Australia [8], and EU countries such as Belgium [9], Spain [10], Finland [11], Lithua- nia [12], and Poland [13]. The authors of such research have observed decreases in physical fitness, even though the results of the assessments of individual motor skills are inconsistent. According to the authors of the above-mentioned studies, the current low level of motor skills of girls and boys is related to a constellation of social, behavioural, physical, psychosocial, and physiological factors, especially to the increase in BMI in children and adolescents in these countries [14].

In the literature, one can find many diagnoses of the biological condition of children and adolescents. However, there is little information on whether reduced physical fitness characterises all the girls and boys examined or whether it occurs in specific groups with particular weight-to-height ratios. Therefore, the aim of this study is to determine the ten-year changes in the physical fitness of girls from Eastern Poland characterised by normal BMI, underweight, overweight, and obesity.

\section{Material and methods}

In 2006, a study was carried out into the basic somatic features and physical fitness of youth from lower and upper secondary schools living in the Lubelskie and Podlaskie Provinces, as part of principle research at the University of Physical Education, AWF, in Warsaw (DS. 45). We randomly selected 
120 schools from a list of educational institutions provided by the local education authorities, making sure that they reflected the population distribution of the area and trying to choose an equal number of schools in each province. The results of the anthropometric measurement performed on 5,760 girls aged 13-18 years were used for the purposes of the current analysis. Measurements were taken in the same schools in 2016 (as part of principle research at AWF in Warsaw, DS. 203), and the results recorded for 2,669 female students aged 13-18 years were analysed. The number of girls who participated in the two measurements, taking into account their calendar age, is presented in Table 1.

Table 1. Number of girls from the Podlaskie and Lubelskie Provinces examined in the study

\begin{tabular}{|c|c|c|c|c|c|c|c|}
\hline Age & 13 & 14 & 15 & 16 & 17 & 18 & Total \\
\hline 2006 & 666 & 940 & 880 & 1053 & 948 & 1273 & 5760 \\
\hline 2016 & 519 & 436 & 416 & 398 & 444 & 456 & 2669 \\
\hline
\end{tabular}

Source: own research.

The study was carried out in compliance with the principles outlined in the Helsinki Declaration and was accepted by the Research Ethics Committee of the University of Physical Education in Warsaw.

The anthropometric measurements were performed in accordance with generally accepted anthropometric techniques (based on IBP recommendations). The data collected regarding body weight and height were used to calculate the Body Mass Index (BMI), which measures the ratio of weight in kilogrammes to squared height in metres. Physical fitness was assessed by means of the EUROFIT test battery [15]. On the basis of the recommendations of the International Obesity Task Force and the cut-off points determined by Cole et al. $[16,17]$, the participants were divided into groups, taking into account underweight and excess body weight. The following groups were established: Group 1 with grade 3 and grade 2 underweight, Group 2 with grade 1 underweight, Group 3 with a normal weight-to-height ratio, Group 4 with overweight, and Group 5 with obesity. We calculated the percentages of girls with underweight, normal weight, overweight, and obesity. The statistical significance of the differences between the numbers of participants qualified for each of the BMI groups established in 2006 and the corresponding groups from 2016 was determined using the $\chi^{2}$ test.

The material collected in 2006 was subjected to further statistical processing; we calculated the arithmetic means and the measures of dispersion for the results obtained in particular Eurofit tests. The calculations, considering calendar age, were made both for the whole population and for groups with different weight-to-height ratios. These values were used as a point of reference for analysing the differences between the girls examined in 2016 and those assessed ten years earlier. For this purpose, all the individual results of physical fitness tests from 2016 were normalised to the results of those from 2006 using a $\mathrm{T}$ point scale ( 50 points). Such a procedure made it possible to homogenise the fitness test units, and calculating the mean of all the motor measurements in the group made it possible to assess overall fitness, which was treated as a statistical category [18]. Such calculations were carried out within the subgroups determined according to BMI criteria and for the whole group. Using the aforementioned principle, the results of girls belonging to particular BMI subgroups assessed in 2016 were normalised to the results of those examined in 2006. Arithmetic means and measures of dispersion of the point values of each of the fitness tests were then calculated for the entire population analysed. The statistical significance of differences between the mean values obtained in 2006 and 2016 was verified with Student's t-test for independent samples.

\section{Results}

In the decade 2006-2016, there was a significant decrease in the percentage of girls with grade 1 underweight (3.44\%) and an increase in the percentage of those with overweight $(2.71 \%)$ and obesity $(2.87 \%)$. When it comes to the groups with considerable underweight and normal BMI, the differences between the percentages of subjects were small (Tab. 2). However, the changes observed were not homogeneous across groups of different calendar ages. For the age of 13-15 years, there was a statistically significant decrease in the percentage of girls in groups with grade 1 and 2 underweight (1.72\% and 4.23\%). On the other hand, the percentages of overweight $(2.48 \%)$ and obese $(2.70 \%)$ girls increased. Less considerable differences were found in girls aged 16-18 years, as only a significant increase in the percentages of overweight (2.33\%) and obese $(2.94 \%)$ girls was observed. In other groups determined according to BMI criteria, there was only a tendency only for the percentages of subjects with underweight and normal BMI to decrease.

Table 2. Percentages of girls in groups with normal BMI, underweight, overweight, and obesity

\begin{tabular}{|c|c|c|c|c|c|c|}
\hline $\begin{array}{c}\text { Age in } \\
\text { years }\end{array}$ & $\begin{array}{c}\text { Year of } \\
\text { research }\end{array}$ & Group 1 & Group 2 & Group 3 & Group 4 & Group 5 \\
\hline \multirow{3}{*}{$13-15$} & 2006 & 3.97 & 11.53 & 77.75 & 6.11 & 0.64 \\
\cline { 2 - 7 } & 2016 & 2.25 & 7.30 & 78.51 & 8.59 & 3.34 \\
\cline { 2 - 7 } & $X^{2}$ test & $9.41^{*}$ & $17.80^{*}$ & 0.04 & $8.49^{*}$ & $46.72^{*}$ \\
\hline \multirow{4}{*}{$16-18$} & 2006 & 4.83 & 13.96 & 77.54 & 3.55 & 0.12 \\
\cline { 2 - 7 } & 2016 & 6.12 & 12.08 & 72.71 & 5.88 & 3.06 \\
\cline { 2 - 7 } & $X^{2}$ test & 2.95 & 2.37 & 1.76 & $11.71^{*}$ & $90.30^{*}$ \\
\hline \multirow{3}{*}{$13-18$} & 2006 & 4.46 & 12.93 & 77.63 & 4.63 & 0.34 \\
\cline { 2 - 7 } & 2016 & 4.03 & 9.49 & 75.85 & 7.35 & 3.21 \\
\cline { 2 - 7 } & $X^{2}$ test & 0.90 & $19.15^{*}$ & 0.48 & $25.34^{*}$ & $133.00^{*}$ \\
\hline
\end{tabular}

* - statistically significant difference at $\mathrm{p}<0.05$.

Source: own research.

Between 2006 and 2016, no decrease was found in the level of physical fitness of the girls examined, which is confirmed by the results obtained for overall fitness (Tab. 3). However, the results were not consistent in all the Eurofit tests. A statistically significant decrease of $\mathrm{p} \leq 0.05$ was found in the results recorded for the endurance shuttle run (3.63 points), balance (3.27 points), and standing broad jump (1.58 points) tests. During both phases of the study, results at a comparable level were achieved in the sit-and-reach, $10 \times 5 \mathrm{~m}$ shuttle run, tapping, and 30-s sit-up tests. On the other hand, a significant improvement in the results at the level of $\mathrm{p} \leq 0.01$ was noted in hand grip (3.35 points) and bent arm hang ( 2.47 points).

The above-described trends in the Eurofit test results do not, however, indicate whether in all groups selected according to BMI criteria, the direction of the changes was in line with the trend observed for the whole population of girls from Eastern Poland. It is also interesting to explore in which of the groups the ten-year changes in physical fitness were the greatest and in which they were the smallest. On the basis of the results for 
Table 3. T-scale results of physical fitness test results for girls aged 13-18 from 2016 normalised to the results of girls from 2006

\begin{tabular}{|l|c|c|c|c|c|c|}
\hline \multicolumn{1}{|c|}{ Fitness test } & All & $\begin{array}{c}\text { Group } \\
\mathbf{1}\end{array}$ & $\begin{array}{c}\text { Group } \\
\mathbf{2}\end{array}$ & $\begin{array}{c}\text { Group } \\
\mathbf{3}\end{array}$ & $\begin{array}{c}\text { Group } \\
\mathbf{4}\end{array}$ & $\begin{array}{c}\text { Group } \\
\mathbf{5}\end{array}$ \\
\hline Balance & $46.73^{* *}$ & $51.30^{* *}$ & $51.20^{*}$ & $46.39^{* *}$ & $44.39^{* *}$ & $43.41^{*}$ \\
\hline Tapping & 49.78 & $48.77^{*}$ & 50.29 & 49.92 & $47.08^{* *}$ & $47.73^{* *}$ \\
\hline Hand grip & $53.35^{* *}$ & $55.58^{* *}$ & $54.84^{* *}$ & $53.59^{* *}$ & $54.14^{* *}$ & $45.70^{* *}$ \\
\hline $\begin{array}{l}\text { Standing broad } \\
\text { jump }\end{array}$ & $48.42^{* *}$ & 49.03 & $48.49^{*}$ & $48.77^{* *}$ & $48.32^{*}$ & $48.20^{*}$ \\
\hline Sit-ups & 50.33 & 50.90 & 50.78 & $52.00^{* *}$ & 50.01 & $44.40^{* *}$ \\
\hline Bent arm hang & $52.47^{* *}$ & $53.65^{* *}$ & $50.97^{*}$ & $51.50^{* *}$ & 49.22 & $55.54^{* *}$ \\
\hline $\begin{array}{l}\text { Endurance } \\
\text { shuttle run }\end{array}$ & $46.37^{* *}$ & $47.21^{* *}$ & $48.68^{*}$ & $46.46^{* *}$ & $43.33^{* *}$ & $41.94^{* *}$ \\
\hline $\begin{array}{l}10 \times 5 \text { m shuttle } \\
\text { run }\end{array}$ & 50.39 & 50.19 & $51.41^{*}$ & 50.45 & 49.48 & 50.16 \\
\hline Sit-and-reach & 49.73 & $52.70^{* *}$ & $51.96^{* *}$ & 49.70 & 49.61 & $48.24^{*}$ \\
\hline Overall fitness & 49.97 & $50.73^{*}$ & $50.94^{*}$ & 50.14 & $48.48^{* *}$ & $46.02^{* *}$ \\
\hline
\end{tabular}

* - statistically significant difference at $\mathrm{p}<0.05$ (Student's t-test);

** - statistically significant difference at $\mathrm{p}<0.01$ (Student's t-test).

Source: own research.

overall fitness, it can be concluded that in the decade analysed, the greatest negative changes occurred in obese girls (3.98 points), followed by overweight girls (1.52 points), and the differences were statistically significant at the level of $p \leq 0.01$. On the other hand, a significant improvement in the results at $\mathrm{p} \leq$ 0.05 was noted in underweight girls ( 0.73 and 0.94 point for Groups 1 and 2, respectively). No significant differences were found for the group with normal BMI. The analysis of individual samples showed that between 2006 and 2016, among girls with underweight, there was a statistically significant improvement of $\mathrm{p} \leq 0.01$ in balance, hand grip, bent arm hang, and sitand-reach, as well as in the subjects with grade 1 underweight in the $10 \times 5 \mathrm{~m}$ shuttle run. Lower results were observed in the endurance shuttle run ( $\mathrm{p} \leq 0.01)$ and tapping $(\mathrm{p} \leq 0.05)$ tests in group 1 as well as the standing broad jump test in group 2 ( $\mathrm{p} \leq$ 0.05). In the remaining fitness tests, the results were at a similar level in the two measurements. It should be emphasised that in girls with normal BMI, the directions of changes in physical fitness were similar to the ones described above for the whole population examined; it was only in the 30-s sit-up test that a significant improvement in the results was noted $(\mathrm{p} \leq 0.01)$. In contrast, among girls with excess body weight, unfavourable secular trends were found in balance ( $\mathrm{p} \leq 0.01)$, tapping ( $\mathrm{p} \leq$ $0.01)$, standing broad jump ( $\mathrm{p} \leq 0.05)$, and endurance shuttle run ( $\mathrm{p} \leq 0.01)$, and additionally in the obese group, in 30-s situps $(\mathrm{p} \leq 0.01)$ and sit-and-reach $(\mathrm{p} \leq 0.05)$. Favourable changes at $\mathrm{p} \leq 0.01$ were observed in hand dynamometry in overweight girls and in bent arm hang in obese girls. No significant differences were observed in the other fitness tests.

\section{Discussion}

The global trend consisting in the increase in overweight and obesity, described in the introduction, is also apparent in Poland. Currently, Polish youth, including pupils from the Lubelskie and Podlaskie Provinces, are less overweight and obese in comparison to their peers from most European Union countries, the USA, or Canada [14]. An analysis of the literature from 2005-2015 carried out by Malczyk [19] showed significant abnormalities in the nutritional status of children and adolescents in Poland. On average, underweight affects between 3\% and $18 \%$ of boys and up to $20 \%$ of girls. The percentage of overweight children and adolescents oscillates around $12-15 \%$, and the percentage of those with obesity is approximately $5-11 \%$. Despite growing knowledge of the risk factors for excess weight and other chronic non-infectious diseases, these figures continue to increase. A national-scale study involving a large sample of Polish children and youth found that the incidence of obesity has increased about three-fold in boys and as much as tenfold in girls in the past 30 years. It was also found that $16.4 \%$ of children and adolescents aged 7-18 years were overweight and obese and that the figures were not the same in all regions of the country [20]. The current study also revealed a significant increase in the percentage of overweight and obese girls, which was not observed in an analysis of the changes in the twenty years preceding the time period analysed in this study [21]. Therefore, we would argue that it is questionable to include the eastern provinces of the country among regions with a low risk of child overweight and obesity, as suggested by Grajda et al [5]. The findings of the current study lead to the conclusion that the slower rate at which socio-economic development is occurring in Eastern Poland is associated with slower negative biological changes in the young generation, and the pace of these changes tends to increase with the improvement of the socio-economic situation of the inhabitants of these areas. It should be stressed that the Lubelskie and Podlaskie Provinces are among the less economically developed regions of Poland, which are to a greater extent affected by unemployment [22]. In order to confirm these observations, a broader, national-scale study should be carried out.

The increasing prevalence of excess body weight to a large extent stems from the development of civilisation. This is related to the wide availability of rapid means of transport and communication, household appliances, and other everyday life conveniences. Some of the positive effects of these changes are that they have made it possible to spend more time during the day and year on education, extra-curricular activities, and work. However, these changes have also had a negative impact on the functioning of the human body. One phenomenon which is detrimental to human health is the excessive use of television and the Internet. Fascinated by the opportunities offered by multimedia (which, thanks to computers and the Internet, make it possible to learn about the world and communicate with others without leaving one's room) and absorbed by their mobile phones, children and youth are increasingly spending their free time passively. This inactive lifestyle is reflected not only in increased body weight, but also in reduced physical fitness [23, 24, 25].

A decrease in the physical fitness levels of children and adolescents observed in many countries in Europe and worldwide was also noted in national-scale studies in Poland which compared observations made on large samples in the years 19791989-1999-2009. In the first decade analysed, there was a minor improvement in the fitness test results of the girls and boys examined, and in the second decade, a decline in performance was observed. The data for 1999-2009 showed a further decrease in physical fitness $[13,18]$. On the basis of a review of the literature devoted to this issue, it can be concluded that the changes occurring in the physical fitness of children and adolescents do not have the same nature in all regions in Poland. Ignasiak et 
al. [26], who examined students of schools in the Dolnośląskie Province in the years 2001-2002 and 2010-2011, observed decreases in the results in the tapping, 30-s sit-up, and sit-andreach tests. The authors found positive changes for the $10 \times 5$ $\mathrm{m}$ shuttle run and hand grip tests and noted that the results in standing broad jump had stabilised. Different changes were observed in girls and boys from Cracow [27]. Participants of a series of studies conducted in 2010 performed better than their peers examined in 2000 in all the Eurofit tests; the only exception was standing broad jump, for which the results were on the same level in both measurements. Studies carried out in Eastern Poland in 1986-1996-2006 showed a similar level of physical fitness in girls in the first decade and its decrease in the second decade [28]. On the basis of the results of the current study, it can be concluded that in recent years, in the eastern provinces of Poland, physical fitness has not decreased in girls, but the level of motor skills has changed, which may indicate adaptation to a changing environment. Particularly alarming is the fact that the greatest negative changes in motor tests were found in girls with excess body weight. This is especially worrying as such young people already have the lowest physical fitness [14]. It should be emphasised that the greatest negative changes in functional development occurred in groups in which the greatest adverse changes in weight-to-height ratios were observed.

In all groups selected according to BMI criteria, similarly as is the case for adolescents from many countries [6], negative changes in cardiorespiratory endurance, which have an adverse impact on body function, were observed. It should be borne in mind that obesity leads to the development of many health disorders such as cardiac ischemia, hypertension, type 2 diabetes, colorectal cancer, or prostate cancer [29]. Another cause of increased weight-to-height ratios and reduced physical fitness is related to the health awareness of children and their parents and the forms of sports activities offered by educational institutions. In a report on physical education and sport in public schools in Poland [30], the Supreme Audit Office (NIK) gave a negative assessment of the education received by students at the audited schools in terms of the physical education and conditions for practising school sports that were provided. Apart from presenting other critical conclusions, the authors of the report stated that over $24 \%$ of lower and about $38 \%$ of upper secondary school students did not participate in physical education classes. As many as $74 \%$ of schools did not take any preventive measures with regard to this issue. The most frequent reasons why students did not participate in PE lessons were the lack of suitable clothing (33.10\%), justification notes from parents $(22.80 \%)$, and medical certificates (17.70\%). Observations conducted among children and adolescents with overweight and obesity show that girls overestimate the size of their bodies, which is a source of frustration, low self-esteem, and negative self-image, and they are reluctant to participate in physical education classes, fearing criticism from their peers [31]. Many exemptions from physical exercise are not justified. Experts stress that children with many illnesses such as spinal curvature disorders, asthma, obesity, or diabetes should not be exempted from PE classes. Physical activity is one of the elements of the treatment and should take place according to a doctor's recommendations. There is an urgent need to encourage young people to engage in physical activity and to create the right conditions for them to practise it. Inter-ministerial corrective actions should be taken with regard to this matter: new national programmes aimed at improving the physical activity of children and adolescents should be developed and introduced with particular emphasis on students with excess body weight, as this is the group where the greatest negative changes in physical fitness have taken place. The current actions of the state administration are insufficient and are mostly targeted at specific groups of girls and boys, mostly with normal BMI.

\section{Conclusion}

Based on the current analysis, the following conclusions and observations can be formulated:

1. Between 2006 and 2016, the percentage of overweight and obese girls increased, and that of girls with grade 1 underweight decreased, which was not observed in the previous two decades.

2. In the decade analysed, the negative trend in physical fitness observed in previous studies was inhibited in girls. Only differences in the level of motor skills were noted, which may be considered evidence of adaptation to a changing environment consisting in an increase in the level of motor skills used more frequently in everyday life and decline of those used less frequently.

3. In 2006 and 2016, a similar level of physical fitness was observed in the groups with underweight and normal BMI, while its decrease was found in overweight and obese subjects, especially in cardiorespiratory endurance, which may lead to the development of many health disorders.

4. The changes in the weight-to-height ratios and physical fitness of the girls who participated in the study show that there is a need to undertake inter-ministerial corrective actions aimed at improving the physical activity of children and adolescents, with particular emphasis on those with excess body weight.

\section{Literature}

1. Lobstein T., Frelut M.L. (2003). Prevalence of overweight among children in Europe. Obesity Reviews 4, 195-200.

2. Lobstein T., Rugby N., Leach R. (2005). Obesity in Europe - 3. International Obesity Task Force. Brussels.

3. Apfelbacher C.J., Cairns J., Bruckner T., Möhrenschlager M., Behrendt H., Ring J. et al. (2008). Prevalence of overweight and obesity in East and West German children in the decade after reunification: Population-based series of crossectional studies. Journal of Epidemiology and Community Health 62, 125-130. DOI: 10.1136/jech.2007.062117.

4. Fraser L.K., Edwards K.L. (2010). The association between the geography of fast food outlets and childhood obesity rates in Leeds, UK. Health Place 16, 1124-1128. DOI: 10.1016/j. healthplace.2010.07.003.

5. Grajda A., Kułaga Z., Gurzkowska B., Napieralska E., Litwin M. (2011). Regional differences in the prevalence of overweight, obesity and underweight among Polish children and adolescents. Medycyna Wieku Rozwojowego 15, 258-265.

6. Tomkinson G.R., Annandales M., Ferrar K. (2013). Global changes in cardiovascular endurance of children and youth since 1964: Systematic analysis of 25 million fitness test results from 28 countries. Circulation 128, Al3498.

7. Nishijima T., Kokudo S., Ohsawa S. (2003). Changes over the years in physical and motor ability in Japanese youth in 1964-1997. Journal of Sport and Health Science 1, 164-170.

8. Lewis N., Dollmanb J., Dalea M. (2007). Trends in physical activity behaviours and attitudes among South Australian youth between 1985 and 2004. Journal of Science and Medicine in Sport 10, 418-427. DOI: 10.1016/j.jsams.2006.10.005. 
9. Duvigneaud N., Wijndaele K., Matton L., Thomis M., Duquet W., Lefevre J. et al. (2006). Physical activity trends among Flemish youth. In G. Steens (ed.), Moet er nog sport zijn? Sport, beweging en gezondheid in Vlanderen 20022006 (pp. 85-95), Antwerpen: F\&G Partners. [in Dutch]

10. Moliner-Urdiales D., Ruiz J.R., Ortega F.B. (2010). Secular trends in health-related physical fitness in Spanish adolescents: The Avena and HELENA Studies. Journal of Science and Medicine in Sport 13, 584-588. DOI: 10.1016/j. jsams.2010.03.004.

11. Huotari P., Nupponen H., Laakso L., Kujala U. (2010). Secular trends in aerobic fitness performance in 13-18-year-old adolescents from 1976 to 2001. British Journal of Sports Medicine 44, 968-972. DOI: 10.1136/bjsm.2008.055913.

12. Venckunas T., Emeljanovas A., Mieziene B., Volbekiene V. (2017). Secular trends in physical fitness and body size in Lithuanian children and adolescents between 1992 and 2012. Journal of Epidemiology \& Community Health 71, 181-187. DOI: 10.1136/jech-2016-207307.

13. Wolański N., Dobosz J. (2012). Secular trend in motor performance (changes in efficiency over decades). In A. Wilczewski (ed.), Determinants of the development of children and youth from rural areas (pp. 8-45). Biała Podlaska: AWF Warszawa, WWFiS. [in Polish]

14. Saczuk J., Olszewska D., Wasiluk A., Olszewski J. (2011). Physical fitness of boys with overweight and obesity living in the eastern provinces of Poland. Polish Journal of Public Health 121(4), 350- 354. DOI: 10.5604/20834543.1152925.

15. Eurofit. (1988). Handbook for the EUROFIT tests of physical fitness. Rome: Council of Europe.

16. Cole T.J., Bellizzi M.C., Flegal K.M., Dietz W.H. (2000). Establishing a standard definition for child overweight and obesity worldwide: International survey. British Medical Journal 320, 1240-1243.

17. Cole T.J., Flegal K.M., Nicholls D., Jackson A.A. (2007). Body mass index cut offs to define thinness in children and adolescents: International survey. British Medical Journal 335, 194-197. DOI: 10.1136/bmj.39238.399444.55.

18. Przewęda R., Dobosz J. (2005). Growth and physical fitness of Polish youths. Warsaw: University of Physical Education Editions.

19. Malczyk E. (2016). Nutritional status of children and youth in Poland on the basis of literature from the past ten years (2005-2015). Annales Academiae Medicae Silesiensis 70, 56-65. DOI: 10.18794/aams/58971 [in Polish]

20. Charzewska J. (2012). Risk of obesity among children and youth in Poland. In S. Nowacka-Dobosz, A. Zarychta, J. Dobosz (red.), Report on the national debate on factors related to physical education in Poland. Warsaw: AWF. [in Polish]
21. Wasiluk A., Saczuk J. (2015). Underweight, overweight, and obesity in boys and girls at the age of 7-18 years from eastern Poland in the years 1986-2006. Medical Studies 31(2), 99105.

22. Statistics Poland (GUS). (2015). Statistical Yearbook of the Regions - Poland. Warsaw.

23. Kimm S., Glynn N.W., Obarzanek E., Kriska A.M., Daniels S.R., Barton B.A. et al. (2005). Relation between the changes in physical activity and body-mass index during adolescence: A multicentre longitudinal study. Lancet 9482, 301307. DOI: 10.1016/S0140-6736(05)66837-7.

24. Smopokos E., Linardakis M., Papadaki A., Christos Lionis C., Kafatos A. (2012). Secular trends in fitness, moderateto-vigorous physical activity, and TV-viewing among first grade school children of Crete, Greece between 1992/93 and 2006/07. Journal of Science and Medicine in Sport 15, 129135.

25. Hricková K., Junger J. (2016). Physical activity and compensation of body posture disorders in children aged seven. Polish Journal of Sport and Tourism 23, 153-160. DOI: 10.1515/ pjst-2016-0020.

26. Ignasiak Z., SławińskaT., Malina R.M. (2016). Short term secular change in body size and physical fitness of youth 7-15 years in Southwestern Poland: 2001-2002 and 2010-2011. Anthropological Review 79(3), 311-329. DOI 10.1515/anre2016-0023.

27. Kowal M., Cichocka B., Woronkiewicz A., Pilecki M., Sobecki J., Kryst Ł. (2011). Intergenerational changes in body build and acceleration of puberty in children and adolescents aged 7-15 years from the metropolitan population in the light of psychosocial determinants. Kraków: AWF. [in Polish]

28. Saczuk J. (2011). Secular trends and social gradients in the biological development of children and youth from Eastern Poland and environment changes in 1986-2006. Biała Podlaska: WWFiS. [in Polish]

29. Kopelman P.G. (2000). Obesity as a medical problem. $\mathrm{Na}$ ture 404, 635-643. DOI: 10.1038/35007508.

30. Supreme Audit Office (NIK), Department of Science, Education and National Heritage (2010). Information on audit results. Physical education and sport in public schools. Warsaw. [in Polish]

31. Mikiel-Kostyra K., Oblacińska A. (2010). Biological, behavioural, and psychosocial factors determining the body mass (BMI) of 13-year-olds. Research report. Warsaw: IMiD. [in Polish]

Submitted: September 20, 2018.

Accepted: January 10, 2019. 